\title{
Caudal analgesia reduces the sevoflurane requirement for LMA removal in anesthetized children
}

\author{
Joon-Sik Kim ${ }^{1}$, Wyun Kon Park ${ }^{1}$, Min-Huiy Lee ${ }^{1}$, Kyu-Hyun Hwang ${ }^{1}$, Hee-Soo Kim², and Jeong Rim Lee ${ }^{1}$ \\ ${ }^{1}$ Department of Anesthesiology and Pain Medicine, and Anesthesia and Pain Research Institute, Yonsei University College of \\ Medicine, ${ }^{2}$ Department of Anesthesiology and Pain Medicine, Seoul National University College of Medicinie, Seoul, Korea
}

Background: An anesthetic state can reduce adverse airway reaction during laryngeal mask airway (LMA) removal in children. However, the anesthetic state has risks of upper airway obstruction or delayed emergence; so possibly less anesthetic depth is advisable. Caudal analgesia reduces the requirement of anesthetic agents for sedation or anesthesia; it is expected to reduce the sevoflurane requirement for LMA removal. Therefore, we determined the $\mathrm{EC}_{50}$ of sevoflurane for LMA removal with caudal analgesia and compared that to the $\mathrm{EC}_{50}$ without caudal analgesia.

Methods: Forty-three unpremedicated children aged 1 to 6 yr were enrolled. They were allocated to receive or not to receive caudal block according to their parents' consent. General anesthesia were induced and maintained with sevoflurane and oxygen in air. $\mathrm{EC}_{50}$ of sevoflurane for a smooth LMA removal with and without caudal analgesia were estimated by the Dixon up-and-down method. The LMA was removed when predetermined end-tidal sevoflurane concentration was achieved, and the sevoflurane concentration of a subsequent patient was determined by the success or failure of the previous patient with $0.2 \%$ as the step size; success was defined by the absence of an adverse airway reaction during and after LMA removal. $\mathrm{EC}_{50}$ of sevoflurane with caudal block, and that without caudal block, were compared by a rank-sum test.

Results: The $\mathrm{EC}_{50}$ of sevoflurane to achieve successful LMA removal in children with caudal block was $1.47 \%$; $1.81 \%$ without caudal block. The $\mathrm{EC}_{50}$ were significantly different between the two groups $(\mathrm{P}<0.001)$.

Conclusions: Caudal analgesia significantly reduced the sevoflurane concentration for a smooth LMA removal in anesthetized children. (Korean J Anesthesiol 2010; 58: 527-531)

Key Words: Caudal analgesia, Laryngeal mask airway, Sevoflurane.

Received: February 8, 2010. Revised: March 8, 2010. Accepted: March 29, 2010.

Corresponding author: Jeong Rim Lee, M.D., Ph.D., Department of Anesthesiology and Pain Medicine, and Anesthesia and Pain Research Institute, Yonsei University College of Medicine, 250, Seongsan-no, Sinchon-dong, Seodaemun-gu, Seoul 120-752, Korea. Tel: 82-2-2227-3840, Fax: 82-2-2227-7897, E-mail: manya@yuhs.ac

(c) This is an open-access article distributed under the terms of the Creative Commons Attribution Non-Commercial License (http:// creativecommons.org/licenses/by-nc/3.0/), which permits unrestricted non-commercial use, distribution, and reproduction in any medium, provided the original work is properly cited. 


\section{Introduction}

The laryngeal mask airway (LMA) is recommended to be removed when patients are fully awake because of the possibility of complications [1]. However, characteristics of children are different from those of adults, and some children respond poorly to verbal commands; so it is difficult to judge whether the child is awake or lightly anesthetized. Therefore, several reports suggest an anesthetized state for the safe LMA removal in children $[2,3]$.

However, the question is how deep the anesthesia should be, because if the LMA is removed at too deep a level of anesthesia, the patient's airway is at risk of being left unprotected for a relatively long time. So it might be ideal to preserve the advantage of extubation under the anesthetic state while reducing the recovery time after the LMA removal. Though a previous study quantified the sevoflurane concentration required for LMA removal without an airway complication in children [4], it should be useful if any other method can further reduce the sevoflurane requirement.

Neuraxial anesthesia exhibits sedative properties that may reduce requirements for general anesthesia [5-9], and caudal epidural block is one of the most commonly performed regional techniques with a reliable perioperative analgesia in pediatric patients. So it is expected that the caudal analgesia would reduce the sevoflurane requirement for a smooth LMA removal in children.

The purpose of this study was to evaluate how much caudal block reduces the sevoflurane requirement for LMA removal without an airway complication in children. So we determined the $\mathrm{EC}_{50}$ of sevoflurane for a smooth LMA removal in children with and without caudal block and compared the $\mathrm{EC}_{50}$ of sevoflurane of each group.

\section{Materials and Methods}

After the approval by the institutional review board (IRB), forty-three children (1-6 years) of ASA 1, scheduled for elective inguinal hernia repair, were enrolled in this study. Written informed consent was obtained from the parents of each participant. Patients with an abnormal airway, reactive airway disease, chronic respiratory disease, or a history of an upper respiratory tract infection in the preceding 6 -week period were excluded.

The patients were assigned to two groups: to receive caudal analgesia (caudal group) or not (control group), based on parents' consent of caudal analgesia. All children were not premedicated. Upon arrival at the operating room, patients were monitored with pulse oximetry, capnography, inhaled and exhaled sevoflurane concentrations, electrocardiography, and noninvasive arterial blood pressure. Anesthesia was induced using an inhaled technique with 8 vol\% of sevoflurane in oxygen via a pediatric circle system. After loss of consciousness, the sevoflurane was adjusted to $3-3.5 \%$ according to the vital signs of the patient, and the same concentration of sevoflurane was maintained for several minutes until an adequate jaw relaxation was attained for a $\mathrm{LMA}\left(\mathrm{LMA}^{\mathrm{TM}}\right.$, The laryngeal mask company Ltd, UK) insertion. The LMA size was determined by the manufacturer's guidelines, which suggests size 1.5 for $5-10 \mathrm{~kg}$, size 2 for $10-20 \mathrm{~kg}$, and size 2.5 for $20-30 \mathrm{~kg}$. After the LMA insertion and before the operation, patients enrolled in the caudal group received caudal block with $1 \mathrm{ml} / \mathrm{kg}$ of $0.2 \%$ ropivacaine by the attending anesthesiologist. Caudal block was not performed for the patients in the control group. Anesthesia was maintained with sevoflurane in $50 \%$ oxygen in air with a total inflow of $2 \mathrm{~L} / \mathrm{min}$, and the sevoflurane concentration was adjusted in response to clinical signs. Spontaneous ventilation was maintained throughout the anesthetic maintenance of all patients, and the end-tidal $\mathrm{CO}_{2}$ ranged from 35 to $50 \mathrm{mmHg}$ during the procedure.

At the end of the surgery, the inhaled sevoflurane concentration was adjusted to the 'predetermined' concentration in approximately $50 \%$ oxygen in air with a total inflow of $6 \mathrm{~L} /$ min and maintained until the exhaled end-tidal sevoflurane concentration was the same as the inhaled concentration; this steady state was kept for at least $10 \mathrm{~min}$. The 'predetermined' concentration of sevoflurane for a particular patient was determined by the response of the previous patient to a larger or smaller concentration (with $0.2 \%$ as a step size) using Dixon's up-and-down sequential method [10], starting at $1.8 \%$. Because the patients were not randomly allocated, another anesthesiologist, who didn't know whether the caudal block was performed or not, performed a LMA removal for the blinded study being blinded to the predetermined concentration of sevoflurane. This anesthesiologist removed a LMA with the cuff inflated and recorded whether the LMA removal was successful or not. A successful LMA removal was defined as the absence of any coughing, clenching, breath holding, laryngospasm, desaturation to $\mathrm{SpO}_{2}<90 \%$, and gross movement during or within $1 \mathrm{~min}$ of the LMA removal [4,11-13]. If a LMA was removed successfully, the sevoflurane concentration for the LMA removal of the next patient was decreased by $0.2 \%$. Conversely, if any of the above complications developed, a LMA removal was regarded as unsuccessful, and the sevoflurane concentration was increased by $0.2 \%$ in the next patient. After a LMA removal, a facemask of $100 \%$ oxygen was routinely applied for $5 \mathrm{~min}$. If a laryngospasm was suspicious, breath holding persisted for more than $30 \mathrm{~s}$, or tidal volumes were less than $6 \mathrm{ml} / \mathrm{kg}$, positive pressure ventilation was applied. When any complication was settled and adequate ventilation without 
any assistance was confirmed, the patient was transferred to the recovery room. In the recovery room, pain or emergence delirium was controlled by a $1 \mathrm{mcg} / \mathrm{kg}$ intravenous fentanyl injection, with close observation.

Demographic data were collected and presented as a median and range, or mean $\pm \mathrm{SD}$, and were analyzed using the MannWhitney test or Fisher's exact test. Dixon's up-and-down method needs at least six pairs of failure-success for a statistical analysis of $\mathrm{EC}_{50}$, and the number of enrolled patients came from the basis of Dixon's method. In this study, $\mathrm{EC}_{50}$ was calculated from the mean of seven pairs of failure-success. To evaluate the effect of caudal analgesia on the sevoflurane requirement for a successful LMA removal, we compared $\mathrm{EC}_{50}$ of sevoflurane with caudal block to that without caudal block by a rank-sum test. $\mathrm{P}$ $<0.05$ was considered statistically significant.

\section{Results}

The demographic data and the anesthetic duration are presented in Table 1.

Table 1. Patients' Characteristics and Duration of Laryngeal Mask Airway Insertion

\begin{tabular}{lcc}
\hline & Caudal group & Control group \\
\hline Number of patients & 24 & 19 \\
Age (yr) (median/range) & $2.8(1-6)$ & $3.3(1-6)$ \\
Gender (M/F) & $13 / 11$ & $11 / 8$ \\
Weight (kg) (mean/SD) & $14.8(3.9)$ & $15.6(4.7)$ \\
Duration of LMA insertion (min) & 69 & 63 \\
\hline
\end{tabular}

Caudal group received caudal injection of $0.2 \%$ ropivacaine $1 \mathrm{ml} / \mathrm{kg}$ before operation, control group did not. Duration of LMA insertion refers to the elapsed time the patient was maintained in the laryngeal mask airway insertion state. Statistical significance accepted when $\mathrm{P}<0.05$. No significant differences were found between the two groups.

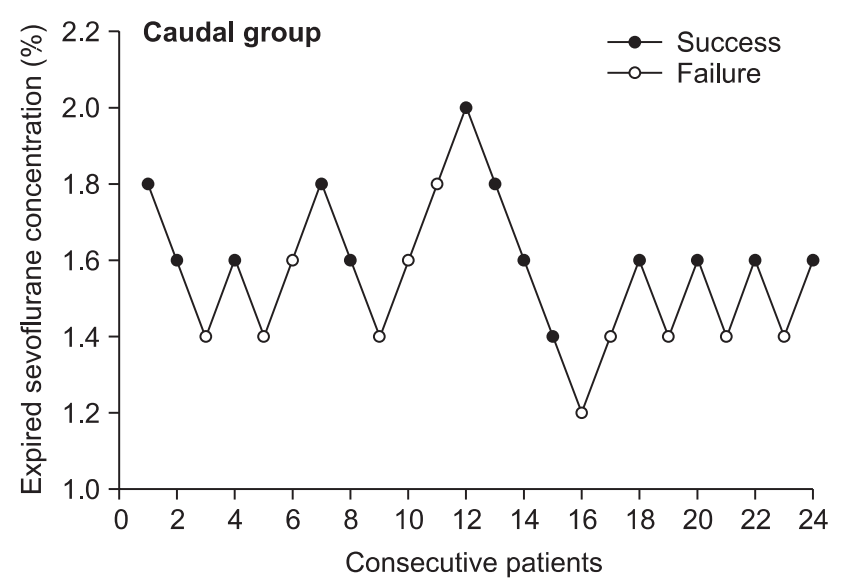

The sequences of successful and unsuccessful LMA removal in each group are shown in Fig. 1. In the control group, $\mathrm{EC}_{50}$ of sevoflurane for LMA removal without airway complication was $1.81 \pm 0.11 \%$. However, in the caudal group, $\mathrm{EC}_{50}$ of sevoflurane was $1.47 \pm 0.08 \%$; these $\mathrm{EC}_{50}$ were significantly different between two groups $(\mathrm{P}<0.001)$.

In the caudal group, 5 of the 13 children with a successful LMA removal required a chin lift for upper airway support. However, in the control group, all 10 children with a successful LMA removal required a chin lift and/or jaw thrust against upper airway obstruction. In unsuccessful LMA removal cases, most of the airway complications that occurred were treated without any problem; mild laryngospasm, which was defined as an inspiratory stridor without complete obstruction, occurred in 5 patients in the caudal group and in 4 patients in the control group. They were treated with continuous positive airway pressure with $100 \%$ oxygen. Desaturation $\left(\mathrm{SaO}_{2}<90 \%\right)$ was not noticed in any of the patients.

\section{Discussion}

From our results, $\mathrm{EC}_{50}$ of sevoflurane for a smooth LMA removal was reduced from $1.81 \%$ to $1.47 \%$ when caudal block was accompanied in pediatric patients aged $1-6$ years.

In children, several studies suggest that the anesthetic state is a better condition for LMA removal in the aspect of reducing airway complication, such as coughing, biting, hypersalivation, and hypoxia [2,3]. However, when an airway device is removed during too deep of an anesthetized state, the risk of prolonged upper airway obstruction or a delayed return of protective reflexes is of main concern $[14,15]$. In the study about the laryngeal tube, which is a supraglottic airway device similar as the LMA, its removal under an anesthetic state of $2 \%$ sevoflurane significantly reduced airway complication but

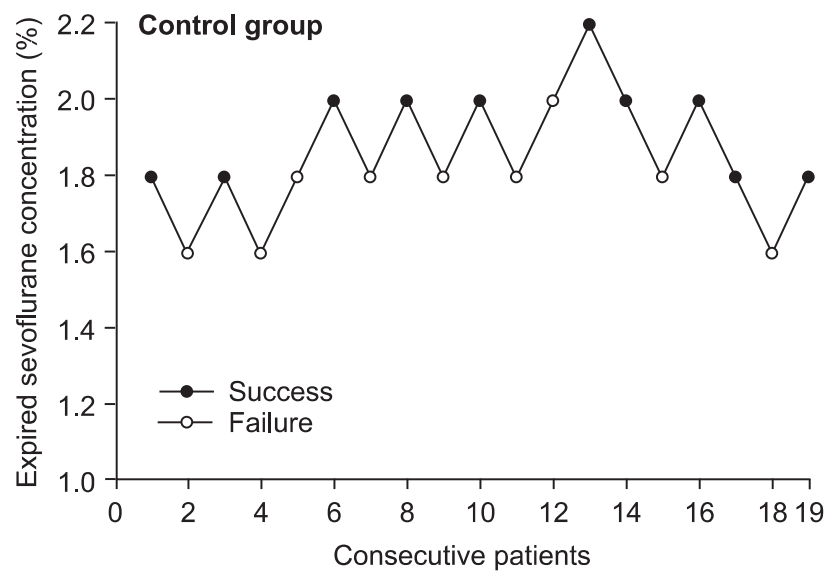

Fig. 1. Responses of consecutive patients in whom LMA removal was attempted at predetermined sevoflurane concentration. Caudal group received caudal injection of $0.2 \%$ ropivacaine $1 \mathrm{ml} / \mathrm{kg}$ before operation, control group did not. A circle represents each patient's data. Success or failure for LMA removal is defined in the text. 
was related to a double incidence of upper airway obstruction compared to its removal in the awake state [16]. In addition, LMA removal in the anesthetic state carries a disadvantage of active pharyngeal reflexes remaining suppressed, resulting in a delayed return of the airway reflex, which causes a potential risk of the patient's airway being left unprotected. Therefore, when a LMA would be removed under the anesthetic state, it is important to apply the least amount of anesthesia, if possible. Several previous studies quantified the adequate depth of anesthesia for LMA removal $[4,11,13]$; but if caudal block could reduce the sevoflurane requirement more, it would be useful because caudal block is a commonly performed procedure without any direct effect on the airway reflex. Our study showed the expected result-that caudal block reduced about $20 \%$ of the sevoflurane concentration for LMA removal without an airway complication.

Xiao et al. studied the effect of caudal anesthesia on the enflurane concentration for LMA removal [12], and the neuraxial anesthesia is known to potentiate sedative drug effects or decrease the minimum alveolar concentration (MAC) of inhalational anesthetics [5-9]. This phenomenon has been explained by several mechanisms. First, pain is considered to play the most important role in the arousal from an anesthesia [17]; caudal analgesia blocks pain from the surgical site, and it decreases the general anesthetic demand. The local anesthetic volume used in this study, $1 \mathrm{ml} / \mathrm{kg}$ of $0.2 \%$ ropivacaine, is expected to block about $\mathrm{T} 12$ dermatome [18]. Therefore the considerable decrease in the sevoflurane requirement for a smooth LMA removal would be induced by the blockade of nociceptive stimuli throughout caudal analgesia. Secondly, neuraxial block reduces the anesthetic requirement to suppress movement in response to a noxious stimulus above the level of sensory block. The afferentation theory proposes that tonic sensory and muscle-spindle activity modulate cerebral activity and maintain a state of wakefulness, and decreased afferent input to the brain could lessen the excitatory descending modulation of the spinal cord motoneurons and suppress motor function [19-21]. Through these mechanisms, caudal block could reduce the sevoflurane requirement for LMA removal despite the fact that caudal block does not have a direct analgesic effect on the upper airway.

The limitation of our study is that there were no data of time intervals between LMA removal and the return of airway reflex in each group. This study was focused on the effect of caudal block on reducing the sevoflurane requirement for a smooth LMA removal, and so was designed to compare sevoflurane concentrations. We thought the interval in the caudal group might be shorter than that in the no-caudal group owing to the difference in the sevoflurane concentration for LMA removal between the two groups; if the time intervals between the two groups were significant, this study would have been weightier.

In conclusion, caudal analgesia can reduce the sevoflurane requirement for a smooth LMA removal-0.6 MAC is sufficient for LMA removal without any airwayz-related complication in $50 \%$ of children while 0.8 MAC is required when caudal analgesia is not performed. Less anesthetic requirements for LMA removal by caudal block would be beneficial for a faster recovery after the LMA removal.

\section{References}

1. Nunez J, Hughes J, Wareham K, Asai T. Timing of removal of the laryngeal mask airway. Anaesthesia 1998; 53: 126-30.

2. Kitching AJ, Walpole AR, Blogg CE. Removal of the laryngeal mask airway in children: anaesthesized compared with awake. Br J Anaesth 1996; 76: 874-6.

3. Laffon M, Plaud B, Dubousset AM, Ben Haj'hmida R, Ecoffey C. Removal of laryngeal mask airway: airway complications in children, anesthetized versus awake. Paediatr Anaesth 1994; 4: 35-7.

4. Lee JR, Kim SD, Kim CS, Yoon TG, Kim HS. Minimum alveolar concentration of sevoflurane for laryngeal mask airway removal in anesthetized children. Anesth Analg 2007; 104: 528-31.

5. Ben-David B, Vaida S, Gaitini L. The influence of high spinal anesthesia on sensitivity to midazolam sedation. Anesth Analg 1995; 81: 525-8.

6. Tverskoy M, Shifrin V, Finger J, Kissin I. Subarachnoid bupivacaine blockade decreases midazolam and thiopental hypnotic requirements. J Clin Anesth 1994; 6: 487-90.

7. Tverskoy M, Shifrin V, Finger J, Flyshman G, Kissin I. Effect of epidural bupivacaine block on midazolam hypnotic requirements. Reg Anesth 1996; 21: 209-13.

8. Inagaki Y, Mashimo T, Kuzukawa A, Tsuda Y, Yoshiya I. Epidural lidocaine delays arousal from isoflurane anesthesia. Anesth Analg 1994; 79: 368-72.

9. Hodgson PS, Liu SS. Epidural lidocaine decreases sevoflurane requirement for adequate depth of anesthesia as measured by the bispectral index monitor. Anesthesiology 2001; 94: 799-803.

10. Dixon WJ. Staircase bioassay: The up-and-down method. Neurosci Biobehav Rev 1991; 15: 47-50.

11. Xiao W, Deng X. The minimum alveolar concentration of enflurane for laryngeal mask airway extubation in deeply anesthetized children. Anesth Analg 2001; 92: 72-5.

12. Xiao W, Deng X, Tang G, Lu M, Xu K. Caudal anesthesia reduces the minimum alveolar concentration of enflurane for laryngeal mask airway removal in boys. Can J Anesth 2002; 49: 194-7.

13. Shim YH, Shin CS, Chang CH, Shin YS. Optimal end-tidal sevoflurane concentration for the removal of the laryngeal mask airway in anesthetized adults. Anesth Analg 2005; 101: 1034-7.

14. Ishikawa T, Isono S, Tanaka A, Tagaito Y, Nishino T. Airway protective reflexes evoked by laryngeal instillation of distilled water under sevoflurane general anesthesia in children. Anesth Analg 2005; 101: 1615-8.

15. Patel RI, Hannallah RS, Norden J, Casey WF, Verghese ST. Emergence airway complications in children: a comparison of tracheal extubation in awake and deeply anesthetized patients. 
Anesth Analg 1991; 73: 266-70.

16. Lee J, Kim J, Kim S, Kim C, Yoon T, Kim H. Removal of the laryngeal tube in children: anesthetized compared with awake. Br J Anaesth 2007; 98: 802-5.

17. Eappen S, Kissin I. Effect of subarachnoid bupivacaine block on anesthetic requirements for thiopental in rats. Anesthesiology 1998; 88: 1036-42.

18. Shin SK, Hong JY, Kim WO, Koo BN, Kim JE, Kil HK. Ultrasound evaluation of the sacral area and comparison of sacral interspinous and hiatal approach for caudal block in children. Anesthesiology 2009; 111: 1135-40.
19. Motokizawa F, Fujimori B. Arousal effect of afferent discharges from muscle spindles upon electroencephalograms in cats. Jpn J Physiol 1964; 14: 344-53.

20. Lanier WL, Iaizzo PA, Milde JH, Sharbrough FW. The cerebral and systemic effects of movement in response to a noxious stimulus in lightly anesthetized dogs. Possible modulation of cerebral function by muscle afferents. Anesthesiology 1994; 80: 392-401.

21. Doufas AG, Wadhwa A, Shah YM, Lin CM, Haugh GS, Sessler DI. Block-dependent sedation during epidural anaesthesia is associated with delayed brainstem conduction. Br J Anaesth 2004; 93: 228-34. 